\title{
Design and Analysis of Micro-Solar Power Systems for Wireless Sensor Networks
}

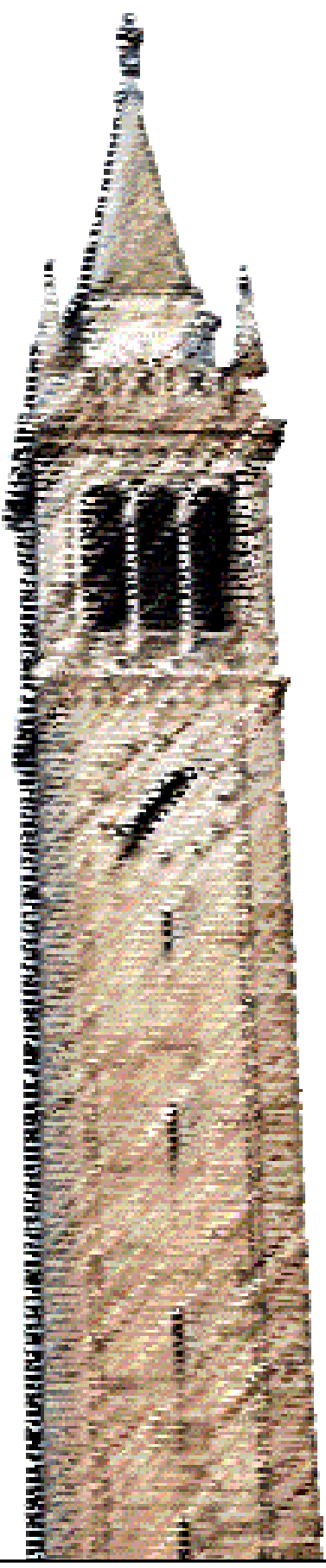

Jaein Jeong

Xiaofan Fred Jiang

David E. Culler

Electrical Engineering and Computer Sciences University of California at Berkeley

Technical Report No. UCB/EECS-2007-24

http://www.eecs.berkeley.edu/Pubs/TechRpts/2007/EECS-2007-24.html

February 6, 2007 
Copyright (C 2007, by the author(s).

All rights reserved.

Permission to make digital or hard copies of all or part of this work for personal or classroom use is granted without fee provided that copies are not made or distributed for profit or commercial advantage and that copies bear this notice and the full citation on the first page. To copy otherwise, to republish, to post on servers or to redistribute to lists, requires prior specific permission. 


\title{
Design and Analysis of Micro-Solar Power Systems for Wireless Sensor Networks
}

\author{
Jaein Jeong, Xiaofan Jiang and David Culler \\ EECS Department, University of California \\ Berkeley, CA 94720 \\ \{jaein,fxjiang,culler\}@eecs.berkeley.edu
}

\begin{abstract}
Wireless Sensor Networks are fundamentally limited by their energy storage resources and the power they obtain from their environment. Several micro-solar powered designs have been developed to address this important problem but little analysis is available on key design trade-offs. We provide an empirical and mathematical analysis of two leading competitors (Heliomote and Trio) and develop a taxonomy of the micro-solar design space, identify key components, design choices, interactions, difficulties and trade-offs.
\end{abstract}

\section{INTRODUCTION}

Autonomous long-term monitoring of the environment is one of the wireless sensor network (WSN) visions. However, limitation of energy supply has constantly impeded the progress of WSN towards large scales and true autonomous operations. In recent years, energy harvesting, especially, solar energy harvesting has become increasingly important as a way to improve lifetime and maintenance cost of WSN. Compared to well-addressed macro-solar power systems, the solar energy harvesting for micro-solar power systems is more constrained in energy budget and use of energy, and is under active research.

Several micro-solar powered designs have been developed from different institutions with a specific set of requirements such as lifetime, simplicity, cost and so on (Table 1). For example, Heliomote and Trio, which are two leading designs of micro-solar power systems show different points in the design space. Heliomote, in favor of simplicity, employed single-level energy storage and hardware-controlled battery charging. Whereas, Trio was designed for lifetime and flexibility and employed two-level energy storage and softwarecontrolled battery charging. However, these previous designs have a limitation: their performance evaluation shows that their systems operate correctly under a set of conditions while providing little analysis on how well they will perform in the entire range of situations encountered in micro-solar power systems.

Our contributions in this paper are three-fold: First, we propose a model for micro-solar power systems and develop a taxonomy of the micro-solar design space identifying key components, design choices, interactions, difficulties and tradeoffs. Second, we provide an empirical and analytical analysis on two leading competitors (Heliomote and Trio) as a concrete example of micro-solar powered systems. Third, we propose a design guideline for micro-solar power systems based on the analysis of previously designed systems.
Table 1: Examples of micro-solar power systems

\begin{tabular}{|l|l|l|}
\hline & Goal & Key features \\
\hline $\begin{array}{l}\text { Prometheus } \\
{[3], \text { Trio }[2]}\end{array}$ & $\begin{array}{l}\text { lifetime, flexibil- } \\
\text { ity }\end{array}$ & $\begin{array}{l}\text { Two-level storage, SW } \\
\text { charging }\end{array}$ \\
\hline Heliomote [7] & simplicity & $\begin{array}{l}\text { HW charging to NiMH } \\
\text { batt }\end{array}$ \\
\hline Everlast [11] & lifetime & MPP tracking \\
\hline RF beacon [9] & proof of concept & $\begin{array}{l}\text { No support for power } \\
\text { disruption }\end{array}$ \\
\hline $\begin{array}{l}\text { Farm monitor- } \\
\text { ing [10] }\end{array}$ & $\begin{array}{l}\text { compactness, re- } \\
\text { liability, cost }\end{array}$ & $\begin{array}{l}\text { HW charging to NiMH } \\
\text { batt }\end{array}$ \\
\hline ZebraNet [13] & compactness & SW charging to Li batt \\
\hline
\end{tabular}

From the measurement on sunny days in northern California during mid-October, we have observed the operation of Trio and Heliomote in terms of solar-cell operating point matching and system-wide solar energy utilization. As for the solar-cell operating point matching, we have found that Trio and Heliomote match their operating points to maximum power points within $6 \%$ and $24 \%$ respectively. Trio matches solar-cell operating point in better way by buffering the solar-cell output with supercapacitor and setting the charging and regulation parameters correctly. As for the system-wide solar energy utilization, we have found that only small portion (33.4\% for Trio, $14.6 \%$ for Heliomote) of solar energy is used. One factor that hurts the system efficiency was overload protection regulator, which wasted two thirds of daily solar energy budget for Heliomote. Although design choices of micro-solar power systems had been studied in isolation, here we study a complete architecture of micro-solar power systems with interplay of their components.

The rest of this paper is organized as follows: Section 2 presents our model for the micro-solar power system; Sections 3, 4, 5 and 6 show how each of the four components of a micro-solar power system can be modeled identifying various design choices. Based on this model, Section 7 compares two leading designs of micro-solar power systems Trio and Heliomote and analyzes the key design points for solar collector efficiency and system efficiency. And this paper is summarized in Section 8.

\section{SYSTEM ARCHITECTURE}

In general, any solar-powered system consists of the following components: the external environment, the solar collector, energy storage and the load (Figure 1). The solar energy from the environment is collected by the solar collector and is made available for the operation of the load. The 


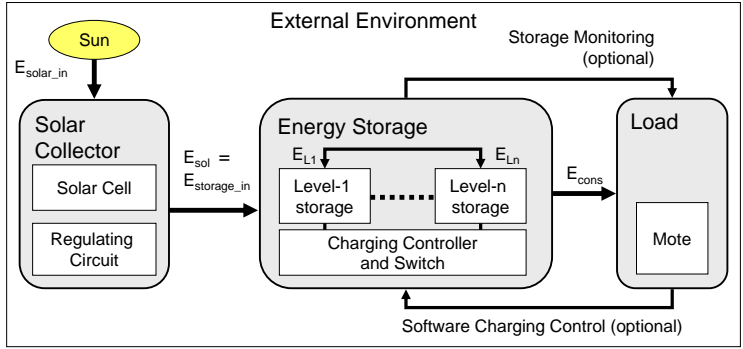

Figure 1: Model for a solar-powered sensor system

Table 2: Evaluation metrics

\begin{tabular}{|c|c|}
\hline Metric & Description \\
\hline$E_{\text {solar_in }}$ & $\begin{array}{l}\text { Available solar energy from the environment to } \\
\text { the solar collector. }\end{array}$ \\
\hline $\begin{array}{l}E_{\text {storage } i n} \\
\text { (or } E_{\text {sol }} \text { ) }\end{array}$ & Available energy collected by the solar-collector. \\
\hline$E_{L 1}, \cdots, E_{L n}$ & The energy stored in level- $i$ storage. \\
\hline$E_{\text {cons }}$ & The energy consumed by the mote. \\
\hline Eff $_{\text {solar }}$ & $\begin{array}{l}\text { Eff } \\
\text { solar }=P_{o p} / P_{\max P} \\
\text { pares output power of the solar cell at its op- } \\
\text { erating point with the maximum possible out- } \\
\text { put power that can be achieved with maximum } \\
\text { power point tracking. }\end{array}$ \\
\hline Eff $_{\text {system }}$ & $\begin{array}{l}\text { Eff }_{\text {system }}=\left(E_{L_{1}}+\cdots+E_{L_{n}}+E_{\text {cons }}\right) / E_{\text {sol }} \\
\text { As a metric of system energy efficiency, it com- } \\
\text { pares the energy that is used for useful purposes } \\
\text { (load or storage) with the incoming energy. }\end{array}$ \\
\hline
\end{tabular}

energy storage is used to buffer the varying energy income and distribute it to the load over the entire duration.

The four components of a solar-powered sensor node interact with each other. The design decision for each component will dictate the energy flows between them and the overall behavior of the system. For the rest of this paper we will evaluate the performance of a micro-solar power system in terms of the energy flow of each component.

Section 3 explains how to model the energy consumption of a mote $\left(E_{\text {cons }}\right)$ with radio duty-cycling. Section 4 shows how to estimate the solar radiation $\left(E_{\text {solar_in }}\right)$ using statistical and mathematical methods. Section 5 discusses the factors that affect the solar-cell operating point $\left(E_{\text {sol }}\right)$. Section 6 discusses the factors that affects the storage capacity and the lifetime. Section 7 shows how to measure the energy flow of the four components in a real experiment and evaluates the performance of Trio and Heliomote based on the measurement. Table 2 lists the metrics that will be used through this paper.

Our study is focused on the energy harvesting for microsolar power systems like solar-powered sensor nodes. Compared to well addressed macro-solar power systems (e.g. electricity generation for residential and commercial buildings), micro-solar power systems have the following characteristics: (1) energy budget is small due to size constraint. (2) energy consumption by the load or other controlling devices (e.g. charging controller, regulator) takes a large fraction of energy budget. (3) There is substantial interaction among the solar-powered system components. Table 3 contrasts the two systems with some examples.

\section{LOAD: SENSOR NODE}

The sensor node (mote) is the end consumer of energy
Table 3: Comparison of the macro-solar system and the micro-solar system

\begin{tabular}{|c|c|c|}
\hline & Macro-solar & Micro-solar \\
\hline Load & $\begin{array}{l}\text { High capacity and high } \\
\text { current. } \\
\text { (e.g. } 60 \mathrm{~W}-110 \mathrm{~V} \text { light } \\
\text { bulb for } 24 \mathrm{hr}: I= \\
0.545 \mathrm{~A}, E=1440 \mathrm{Wh})\end{array}$ & $\begin{array}{l}\text { Small capacity and cur- } \\
\text { rent. } \\
\text { (e.g. Telos mote for } 24 \mathrm{hr} \text { : } \\
I=20 \mathrm{~m} A, V=3 V, E= \\
1.44 W h \text { ) }\end{array}$ \\
\hline $\begin{array}{l}\text { Solar } \\
\text { collec- } \\
\text { tor }\end{array}$ & $\begin{array}{l}\text { Large output power with } \\
\text { less constrained in size. } \\
\text { Cost for MPPT can be } \\
\text { amortized due to high } \\
\text { output power. }\end{array}$ & $\begin{array}{l}\text { Small output power } \\
\text { due to size constraint. } \\
\text { Dynamic impedance } \\
\text { matching like MPPT can } \\
\text { be quite an overhead. }\end{array}$ \\
\hline Storage & $\begin{array}{l}\text { High capacity and cur- } \\
\text { rent required (Lead acid } \\
\text { battery preferred). }\end{array}$ & $\begin{array}{l}\text { High energy density re- } \\
\text { quired (Li+ or NiMH } \\
\text { battery preferred). }\end{array}$ \\
\hline
\end{tabular}

in a micro-solar power system and the amount of energy a mote consumes $\left(E_{\text {cons }}\right)$ determines the capacity planning of a solar-powered sensor node. In order to size the mote energy consumption, we need to understand its main causes of energy consumption: radio communication and sensing. Since a mote draws much higher current when its radio-chip is awake than it is asleep, radio duty-cycling is commonly used as a technique that can save the energy consumption of a mote. Power savings for the sensing device can be achieved in a similar way.

Duty-cycling allows a sensor node to communicate with less energy consumption but sometimes at a cost of increased latency. Figure 2 shows the current consumption pattern of a mote for one hour (radio duty-cycle: $1.56 \%$, radio awake time: $8192 \mathrm{~ms}$, message transmission interval: $4 \mathrm{sec}$ ). We can see that the current consumption at active state is about 64 times larger than the current consumption at sleep state $\left(I_{\text {awake }}=17.3539 \mathrm{~mA}\right.$ and $\left.I_{\text {sleep }}=0.2698 \mathrm{~mA}\right)$. And this large difference justifies the use of duty-cycling for power saving.

A mote's current consumption rate $I_{\text {est }}$ can be estimated with the formula below if the current consumption rates for the sleep state and the active state $\left(I_{\text {sleep }}\right.$ and $\left.I_{\text {awake }}\right)$ are known:

$$
I_{\text {est }}=R \cdot I_{\text {awake }}+(1-R) \cdot I_{\text {sleep }}
$$

The actual current consumption can be different from the estimation from the above formula if we use different traffic patterns. This is because the current consumption for transmission and listening can be different. However, we can still get the benefit from duty-cycling due to the large difference in $I_{\text {awake }}$ and $I_{\text {sleep }}$.

The experimental result that compares the current consumption measurements $\left(I_{\text {avg }}\right)$ and the estimates for different radio duty-cycle rates $\left(I_{\text {est }}\right)$ is shown in Table 4 . The small difference between the measurements and the estimates $(-1.62 \%$ to $0.61 \%)$ implies that we can estimate the current consumption of a mote as a linear function of the duty-cycle rate $R(0<R<1)$. The current consumption value can be somewhere between $I_{\text {awake }}$ and $I_{\text {sleep }}$. Since the transition time is very short compared to the sleep and awake durations, the estimation error of considering just the two states (sleep and awake) is bounded to a small value.

Although we have shown the duty-cycling for a single sensor node, the concept of radio duty-cycling is still valid for a network of sensor nodes using low-duty cycle MAC protocols like S-MAC [12] or B-MAC [5]. These MAC protocols achieve low duty-cycle while maintaining the synchroniza- 
Table 4: Current consumption of the Trio node at sleep and awake state for different duty-cycle rates.

\begin{tabular}{|c|r|r|r|r|r|}
\hline & $\mathbf{1 . 5 6 \%}$ & $\mathbf{6 . 2 5 \%}$ & $\mathbf{1 2 . 5 \%}$ & $\mathbf{2 5 \%}$ & $\mathbf{5 0 \%}$ \\
\hline$I_{\text {avg }}(\mathrm{mA})$ & 0.5276 & 1.327 & 2.4082 & 4.5685 & 8.8537 \\
$I_{\text {sleep }}(\mathrm{mA})$ & 0.2638 & 0.2646 & 0.2764 & 0.2745 & 0.3192 \\
$I_{\text {awake }}(\mathrm{mA})$ & 17.4138 & 17.3417 & 17.3546 & 17.3055 & 17.3618 \\
$I_{\text {est }}(\mathrm{mA})$ & 0.5363 & 1.3376 & 2.4053 & 4.5408 & 8.8119 \\
\hline Deviation & $-1.62 \%$ & $-0.79 \%$ & $0.12 \%$ & $0.61 \%$ & $0.47 \%$ \\
$\frac{I_{\text {avg }}-I_{\text {est }}}{I_{\text {est }}}$ & & & & & \\
\hline
\end{tabular}

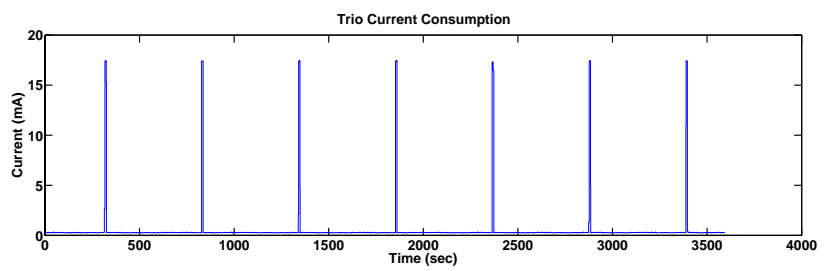

Figure 2: Trio node current consumption at $\mathbf{1 . 5 6 \%}$

tion among the nodes. For example, both S-MAC and BMAC can consume less than $10 \%$ of radio duty-cycle for the latency of $4 \mathrm{sec}$ or longer. The load characteristic affects the rest of the systems in many ways. We discuss its implications to the solar collector in Section 5 and to the storage in Section 6.

\section{EXTERNAL ENVIRONMENT}

The amount of solar radiation $E_{\text {solar_in }}$ depends on the environment condition and it is one of the factors that determines the available energy out of the solar collector $E_{\text {sol }}$. In previous designs, the solar radiation was not carefully modeled: They did not consider the variation in solar radiation $[9,11]$ or just showed the daily solar radiation variation over one to several days $[3,2,10,7,4]$. Kansal et al. [4] presented a bound rule for perpetual operation, but their rule is for generic energy harvesting and does not provide a way to estimate the solar radiation. In this section, we describe two ways to estimate the solar radiation: a statistical method and a mathematical method.

We can estimate the available energy from the sunlight for a given period if the solar cell characteristics and the solar radiation statistics are provided. In order to get the solar radiation statistics, we have used a software called $\mathrm{Me}$ teonorm [1]. Based on its meteorological database and userentered parameters, Meteonorm estimates the solar energy radiation as the amount of energy for each month: $E_{\text {month }}$ $\left(\mathrm{kWh} / \mathrm{m}^{2}\right)$. Using $E_{\text {month }}$, we can calculate the peak solar hours (PSH), which is the equivalent solar radiation hours assuming that the same amount of solar energy is given at an intensity of $1 \mathrm{~kW} / \mathrm{m}^{2}$. Then, the available energy from a specific solar cell for one day, $E_{\text {solar_in }}$, can be estimated as the product of the peak solar hours (PSH) and the solar cell output power $P_{\text {solar }}$ at $1 \mathrm{~kW} / \mathrm{m}^{2}$, which is usually provide by its manufacturer:

$$
\begin{aligned}
E_{\text {solar_in }} & =\frac{E_{\text {month }}}{\# \text { days }} \\
P S H & =\frac{E_{\text {solar_in }}}{1 \mathrm{~kW} / \mathrm{m}^{2}} \\
E_{\text {sol }} & =P S H \cdot P_{\text {solar }}\left(1 \mathrm{~kW} / \mathrm{m}^{2}\right)
\end{aligned}
$$

Table 5: Average daily solar radiation for each month provided by the Meteonorm software: San Francisco, CA with longitude $\mathbf{- 1 2 2 . 2 2}{ }^{\circ}$ and latitude $37.37^{\circ}$

\begin{tabular}{|c|cccccc|c|}
\hline & Jan & Feb & Mar & Apr & May & Jun & \\
\hline$E_{\text {month }}$ & 67 & 83 & 132 & 170 & 208 & 215 & \\
PSH & 2.16 & 2.96 & 4.26 & 5.67 & 6.71 & 7.17 & \\
\hline & Jul & Aug & Sep & Oct & Nov & Dec & Year \\
\hline$E_{\text {month }}$ & 228 & 202 & 161 & 121 & 75 & 61 & 1718 \\
PSH & 7.35 & 6.52 & 5.37 & 3.90 & 2.50 & 1.97 & 4.71 \\
\hline
\end{tabular}

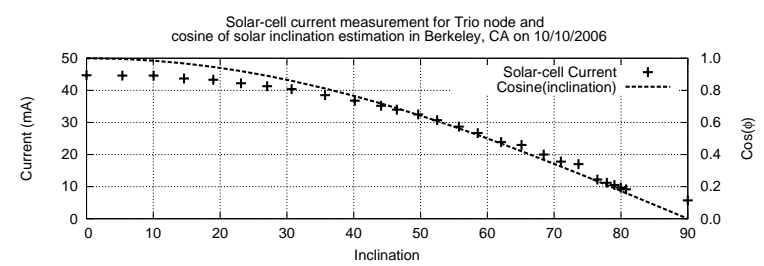

Figure 3: Solar-cell current measurement and cosine of inclination estimation. In the measurement, the solar-cell short-circuit current with a multi-meter at several different inclinations.

For example, Table 5 shows the PSH for each month of the year in San Francisco recorded in Meteonorm.

We can provide insight into the solar radiation using a mathematical model of the sunlight. When the angle of the sunlight from the normal to the solar cell (inclination) is $\phi$, then the effective sunlight that shines on the solar cell is proportional to $\cos \phi$. Figure 3 shows that there is a similar trend between the solar radiation and $\cos \phi$. The inclination $\phi$ depends on the latitude of the experiment location, the angle of the earth's axis, the day of the year and the time of the day. Detailed explanation can be found in [8].

Although we can describe the trend of solar radiation using the statistical and mathematical methods, the actual solar radiation can vary due to the weather condition and obstruction. Figure 4 shows that the output of the solar cell is greatly reduced when clouds or other objects obstruct a solar cell. The solar cell current (solid line) is less than $5 \mathrm{~mA}$ during the morning time and for a few hours in the afternoon (17:30 to 19:00) even though the predicted value from the solar cell inclination is much higher (dotted line). This is because the experiment site is obstructed either by the building (morning) or by the trees (afternoon). We can also see that the solar cell output for $7 / 1 / 2006$ is lower than for $6 / 30 / 2006$. This is because of the cloudy weather.

The available solar energy determines the capacity planning of a micro-solar power system. For example, Figure 5 shows one-day trend of solar-cell power $P_{\text {sol }}$ of Trio node on $6 / 30 / 2006$. Since the daily solar energy $E_{\text {sol }}=\int P_{\text {sol }} d t$ is available during only a few hours a day, the energy storage should be sized so that $E_{\text {sol }}$ can be stored in a few hours and be distributed over the entire time of the day.

\section{SOLAR COLLECTOR}

In a micro-solar power system, the solar energy from the environment is converted to electric energy by the solar collector. The solar collector includes two main components: the solar cell, which converts the photon into electricity; and the regulator, which conditions the output power of the so- 

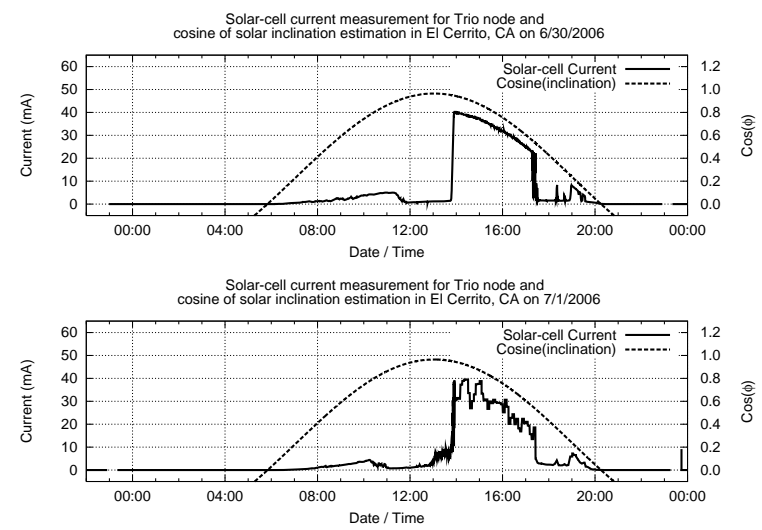

Figure 4: Solar-cell current measurement and effects of obstructions.

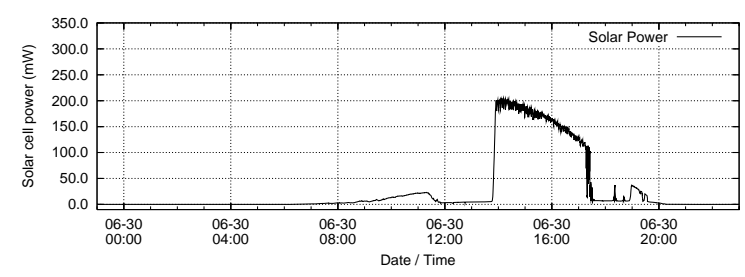

Figure 5: Trio solar-cell power measurement on $6 / 30 / 2006$.

lar cell for energy transfer to the storage. The amount of solar energy out of the solar collector $E_{\text {sol }}$ is determined by the following factors: (1) solar radiation, (2) solar-cell characteristics, (3) the operating point of solar-cell. Item (1) was discussed in Section 4. In this section, we discuss (2) and (3).

The solar-cell I-V curve in Figure 6 describes how the output current of a solar cell behaves at a certain radiation condition. The solar cell outputs short circuit current $I_{s c}$ when the load impedance is set to zero. As the load impedance increases, the output current becomes smaller. When the load impedance is set to open circuit, the output current becomes zero and we call the voltage at this condition as open circuit voltage $V_{o c}$. The solar cell outputs the maximum power when the product of $\mathrm{I}$ and $\mathrm{V}$ is the maximum. This maximum power point (MPP) is shown as $\left(V_{\max P}, I_{\max P}\right)$ in Figure 6 . As the solar irradiance increases or decreases, the I-V curve moves up or down. Thus, a solar cell can be described as a sequence of I-V curves with each I-V curve corresponding to a particular solar irradiance condition (Figure 7).

The regulator performs the following three things (Figure 8): (1) protecting the back flow from energy storage to solar-cell (2) protecting the energy storage from overload (3) setting the operating point for the solar cell.

The back flow protection circuit is to prevent the energy storage from being drained to the solar cell when there is little sunlight, such as during the night or rain. A forwardbiased diode is used for this purpose. The overload protection circuit protects the storage elements from being overloaded by high solar-cell current. A reverse-biased diode or other switching circuit can be used.
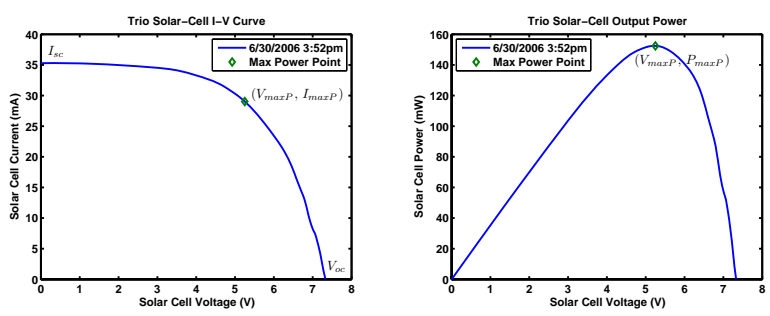

Figure 6: (a) Solar-cell I-V characteristic, (b) Solarcell V-P graph with MPP

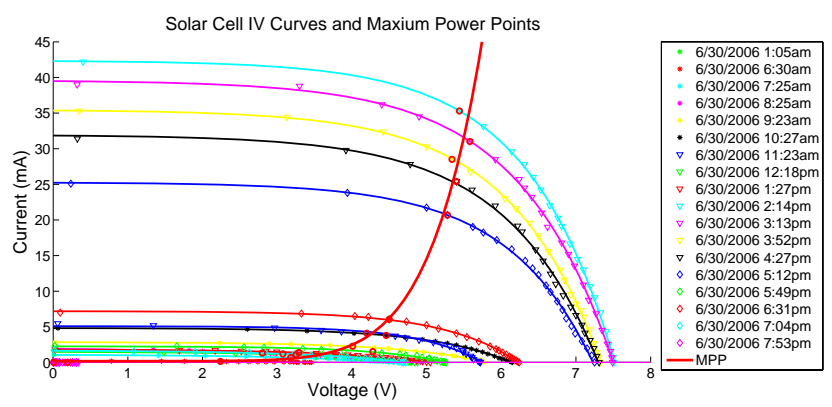

Figure 7: A series of solar-cell I-V curves for Trio node solar cell on 6/30/2006 in El Cerrito, CA

Figure 9 shows the effects of the regulator on the operating point of the solar cell. The overload protection circuit determines the upper bound of the operating point $\left(V_{\text {overload }}\right)$, and the actual operating point is determined by the charging controller in the energy storage or the regulator $\left(V_{o p}\right)$. In order to maximize the power transfer from the solar cell, it is recommended that the regulating circuit operate near maximum power point (MPP), which is the point in the I-V curve where $P=I \cdot V$ is maximized.

As a way of achieving maximum power transfer, a maximum power point tracker can be used (e.g. Everlast [11]). An active circuit is usually required when the energy signal is near DC. While this may sound like an attractive option, care needs to be taken when using it in practice. Since the power a sensor node operates at is usually very small (in the $\mathrm{mW}$ range), the energy consumed by the maximum power point tracker becomes significant and sometimes more than what it can save.

\section{ENERGY STORAGE}

Energy storage is the group of storage elements used to buffer the energy coming from the solar collector and deliver them to the mote in a predictable fashion. Energy storage can consist of any number of storage elements grouped together in some configuration. The challenge is to find the desirable configuration and combination of storage elements such that the requirements are maximized.

In general, designing the energy storage involves choosing the storage elements and charging mechanism for correct operation and efficient energy transfer. As the first step of storage design, a system designer should consider system requirements as follows:

- Lifetime: The lifetime of the energy storage is determined by the maximum charge or discharge cycles. 


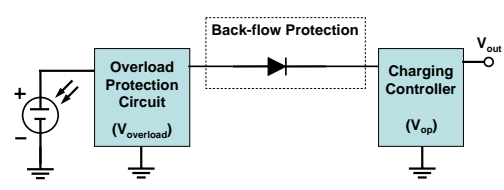

Figure 8: Functions of regulator

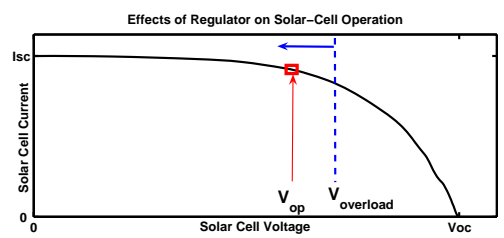

Figure 9: Effects of regulator on solar-cell operation

The lifetime should be long enough to avoid frequent replacement.

- Capacity: The energy storage should be large enough to support the operation of the end device under the disruption of solar energy. The capacity of the storage should be proportional to the blackout period desired to support. It is important to realize that the energy input is not a constant, and therefore the buffers need to be sized appropriately to accommodate environmental variations. Other than nominal capacity of the storage element, self discharge rate and memory effects also affects the storage capacity. The effective storage capacity should be corrected for these factors.

- Current draw: The energy storage should also be able to support a short burst of the power requirement (the maximum current draw of the end device).

- Size and weight: A system designer should pick energy storage elements that meet the requirement of the application.

Table 6 lists the characteristics of different storage elements. For micro-solar power systems, NiMH battery, Li+ / $\mathrm{Li}+$ polymer or supercapacitor is desirable. The $\mathrm{NiCd}$ battery is not preferred due to its smaller energy density, memory effects and harmful environmental effects. Depending on the priority of requirements: NiMH battery (capacity and cost), $\mathrm{Li}+/ \mathrm{Li}+$ polymer (high energy density and capacity), or supercapacitor (lifetime) can be chosen.

Configuring the connection between the power supply and the energy storage and the connection between the energy storage and the mote presents another opportunity for optimizing the operating point. More importantly, different configurations of energy storage elements allow a great freedom in how we can best satisfy the various requirements stated above. Compared to using a single type of storage element a combination of storage elements with different capacities has a desirable characteristic: short frequent disruptions are buffered by a smaller capacity storage while larger but less frequent disruptions are buffered by a larger capacity storage. In this way, small disruptions do not affect the lifetime of larger storage element, which may often have less charge cycles. A side effect of two-level storage is additional energy loss. The charging mechanism should be designed to minimize this loss.

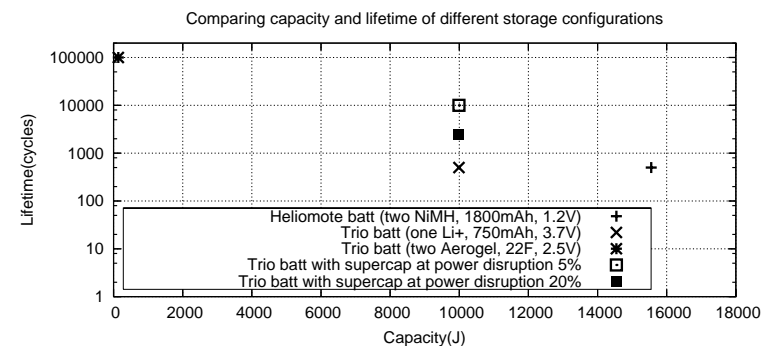

Figure 10: Comparing capacity and lifetime of different storage configurations (estimated from manufacturer-provided storage specification)

Figure 10 compares the capacity and the lifetime of different storage configurations for Trio and Heliomote. Compared to the case using only a $\mathrm{Li}+$ battery, Trio improves the lifetime of the storage and provides the same overall capacity by using a Li+ battery and a supercapacitor. The improvement in lifetime varies depending on the power disruption rate of the primary storage (supercapacitor).

the charging mechanism is another factor that affects the system performance. Depending on the decisions in the charging mechanism (e.g. when and how much), the amount of energy that can be transferred to the storage can change. Different energy storage has different charging profile and this affects the complexity of the charging mechanism. For example, a NiMH battery has simple charging profile: it can be charged with continuous small current. Whereas, a $\mathrm{Li}+$ battery may require constant-current (CC) followed by constant-voltage $(\mathrm{CV})$. Depending on the system requirement, a system designer can take a trade-off between complexity and more efficient energy transfer.

\section{COMPARATIVE STUDY}

In this section, we introduce two concrete examples of a solar-powered sensor node, Trio [2] and Heliomote ${ }^{1}$ [7] as shown in Figure 11. We have chosen these two platforms for our study because they are relatively well designed and show different design points.

\subsection{Solar-Collector Operation}

In order to evaluate the performance of solar collector of each micro-solar power designs, we can compare the metric

$$
\mathrm{Eff}_{\text {solar }}\left(=P_{o p} / P_{\max P}\right)
$$

of each micro-solar power design. As we defined in Section 2, $P_{o p}$ is the solar-cell output power at the operating point and $P_{\max P}$ is the maximum possible output power that can be achieved with maximum power point tracking.

In order to measure $P_{o p}$ and $P_{\max P}$, we set up two experiments (a) and (b) (Figure 12). In experiment (a), we measure the solar-cell operating voltage $\left(V_{o p}\right)$ and current $\left(I_{o p}\right)$. Then, $P_{o p}$ is calculated as $V_{o p} \cdot I_{o p}$. In experiment (b), we measure the characteristic of a separate solar cell by adjusting the load impedance in multiple steps to read a sequence of $(\mathrm{I}, \mathrm{V})$ pairs. Based on this $\mathrm{I}-\mathrm{V}$ characteristic we can

\footnotetext{
${ }^{1}$ Disclaimer: The Heliomote hardware used in our experiment is a preproduction version, hence its performance may be different if the manufacturer changes the hardware in a later version.
} 
Table 6: Different types of energy storage element for micro-solar power systems

\begin{tabular}{|c|c|c|c|c|c|}
\hline Type & $\mathrm{NiCd}$ & NiMH & $\mathrm{Li}^{+}$ & Li-polymer & Supercap \\
\hline Make & Sanyo & GP & Ultralife & Ultralife & Aerogel \\
\hline Model No. & KR-800AAE & GP180AAHC & UBP005 & UBC001 & B-series \\
\hline \multicolumn{6}{|l|}{ Characteristic of a single storage } \\
\hline Nominal volt / Capacity & $1.2 \mathrm{~V} / 800 \mathrm{mAh}$ & $1.2 \mathrm{~V} / 1800 \mathrm{mAh}$ & $3.7 \mathrm{~V} / 750 \mathrm{mAh}$ & $3.7 \mathrm{~V} / 930 \mathrm{mAh}$ & $2.5 \mathrm{~V} / 22 \mathrm{~F}$ \\
\hline Energy / Cost & $0.96 W h / \$ 1.70$ & $2.16 W h / \$ 2.30$ & $2.78 W h / \$ 11.15$ & $3.44 W h / \$ 14.00$ & $0.0191 W h / \$ 10.00$ \\
\hline weight energy density & $42 \mathrm{Wh} / \mathrm{Kg}$ & $83 W h / K g$ & $163 \mathrm{Wh} / \mathrm{Kg}$ & $156 \mathrm{Wh} / \mathrm{Kg}$ & $1.73 \mathrm{Wh} / \mathrm{Kg}$ \\
\hline volume energy density & $102 \mathrm{Wh} / \mathrm{l}$ & $203 W h / l$ & $297 W h / l$ & $270 \mathrm{Wh} / \mathrm{l}$ & $2.71 \mathrm{Wh} / \mathrm{l}$ \\
\hline charge cycles & $>500$ & $>500$ & $>500$ & $>300$ & $>100,000$ \\
\hline self-discharge (\%/month) & $25-30$ & $30-35$ & $<10$ & $<10$ & $25 \% /$ day \\
\hline memory effects / charging method & Yes / trickle & No / trickle & No / pulse & No / pulse & No / trickle \\
\hline
\end{tabular}
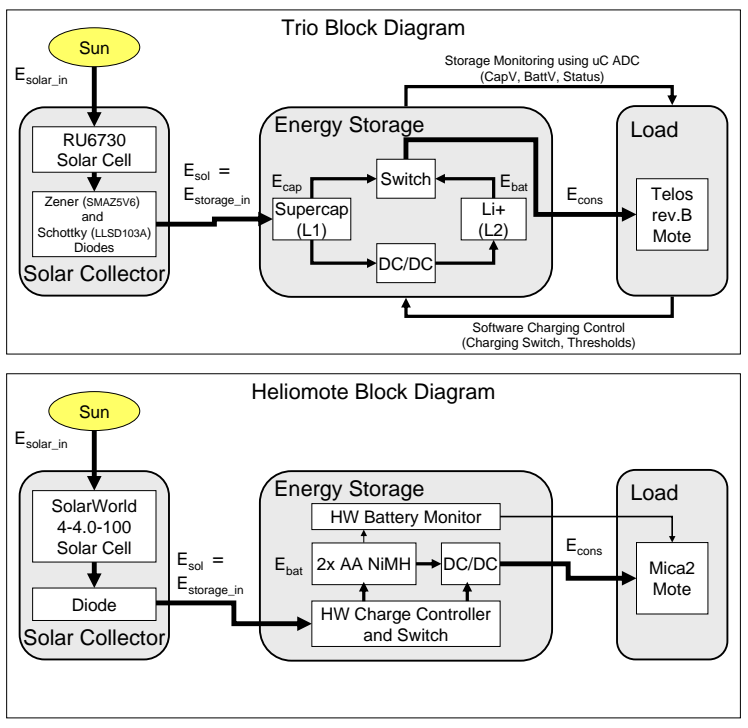

Figure 11: Block diagrams for Trio and Heliomote

find the maximum output power $P_{\max P}\left(=V_{\max P} \cdot I_{\max P}\right)$ as well as other solar-characteristics like open-circuit voltage $V_{o c}$ and short-circuit current $I_{s c}$. This experiment was set up in the field at Richmond Field Station (Richmond, California), where non-obstructed view of the sunlight was provided during most of the daytime. As for the multimeters that measure current or voltage of the device, we used Fluke-189 multimeters, which allowed us to log the voltage and current measurement for many hours.

Figure 13 shows a series of solar cell I-V curves for the solar cells of Trio and Heliomote. Each curve corresponds to the solar- cell I-V characteristic at a particular time of the day and it is marked with corresponding operating point and maximum power point. Table 7 lists the short-circuit current, open-circuit voltage and maximum power point for each curve in Figure 13. In comparing the two systems, we focus on high radiation hours (9AM to 5PM) because the output current of solar cells is too small for practical use outside this time window.

As we can see in Figure 14, the Trio node had $59.67 \mathrm{~mW}$ to $136.10 \mathrm{~mW}$ for $P_{o p}$ and $P_{\max P}$ was $52.96 \mathrm{~mW}$ to $131.65 \mathrm{~mW}$. The deviation between $P_{o p}$ and $P_{\max P}$ as $4.83 \mathrm{~mW}(5.3 \%)$ on the average. We expected that $P_{\max P}$ is larger than $P_{o p}$ because is $P_{\max P}$ means the best possible value if we employ maximum power point tracking. On the contrary, $P_{o p}$ was slightly larger than $P_{\max P}$ and this is due to the manufacturing variation. For the case of the Heliomote node,

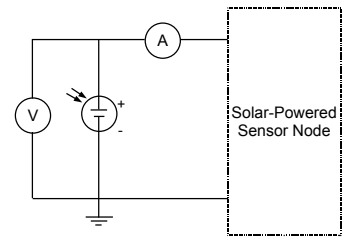

(a)

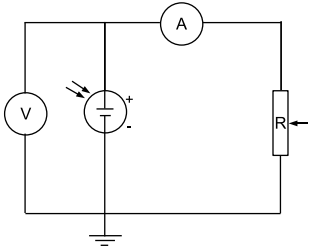

(b)
Figure 12: Experiment set-up for measurement of solar cell output power.

we had $P_{o p} 26.26 \mathrm{~mW}$ to $84.38 \mathrm{~mW}$ and $P_{\max P} 34.42 \mathrm{~mW}$ to $107.50 \mathrm{~mW}$ with the deviation between $P_{o p}$ and $P_{\max P}$ as $-16.75 \mathrm{~mW}(-23.2 \%)$ on the average. We can see that Trio is better matched to MPP than Heliomote.

It is noticeable that the solar-cell output power $P_{o p}$ at the operating point is affected by the solar-cell regulator and the storage charging controller as we mentioned in Section 5. Figure 15 shows this effect for Trio and Heliomote.

For the case of Trio node, the output from the solar cell is buffered in the supercapacitor before it is charged to the battery. The software-based charging controller (Algorithm 1) sets the operating range of the supercapacitor between $\operatorname{Cap}_{L B}(=3.2 \mathrm{~V})$ and $\operatorname{Cap}_{U B}(=4.0 \mathrm{~V})$ while the overload protection voltage $V_{\text {overload }}$ is set to $5.1 \mathrm{~V}$ by the reverse-biased Zener diode. Thus, the output from the solar cell can be transferred to the supercap and the battery without being cut by the overload protection circuit. Heliomote, on the other hand, charges the solar-cell output to the battery without buffering. In this configuration, the overload protection threshold $(=2.8 \mathrm{~V})$ can be directly seen by the solar cell. We can see that the $V_{o p}$ of Heliomote is 2.8, which is the overload protection voltage. This implies that $V_{o p}$ is forced by the overload protection, otherwise it would be located higher than $V_{\text {overload }}$ for better performance.

We also note that the maximum power point of each I-V curve changes as the solar radiation changes. During the high radiation hours, Trio had a range of $0.57 \mathrm{~V}$ for $V_{\max } P$ $(4.87 \mathrm{~V}$ to $5.44 \mathrm{~V})$ and Heliomote had a range of $1.15 \mathrm{~V}(2.87 \mathrm{~V}$ to $4.02 \mathrm{~V})$. We can see that Trio had a smaller range of $V_{\max } P$ than Heliomote. When we set the operating point to a fixed value, having a smaller range in $V_{\max P}$ gives better match to maximum power. The reason why Heliomote has a higher range in $V_{\max P}$ is because its solar cell $\mathrm{I}-\mathrm{V}$ curve has lower curvature than Trio. Figure 16 shows that the I-V curve with smaller curvature (curve B) has larger swing in $V_{\max P}$ than the I-V curve with higher curvature (curve A).

Figure 17 shows the relationship between the output power 


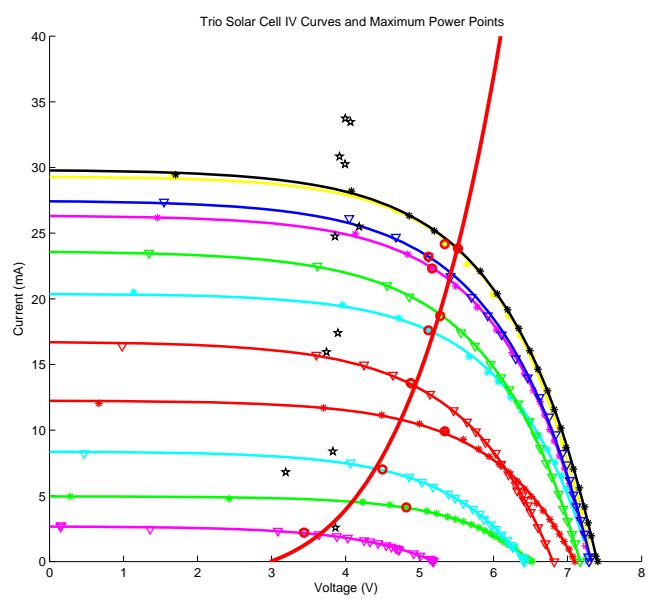

(a) Trio

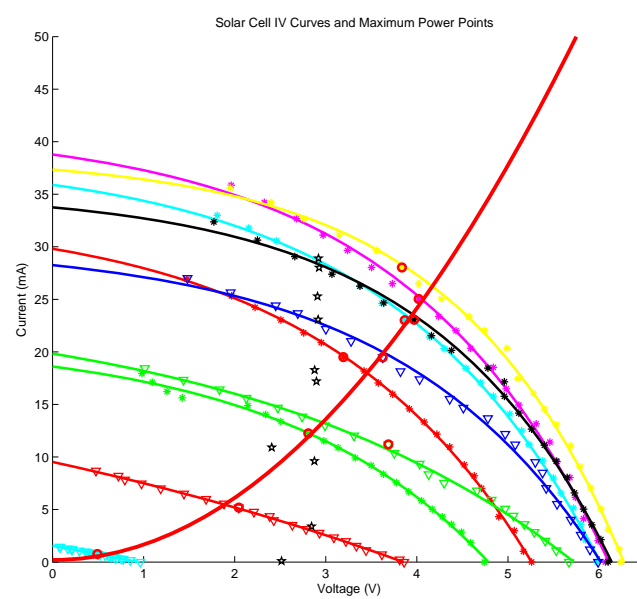

(b) Heliomote

Figure 13: I-V characteristics solar-cells

and the operating voltage for the two systems. The output power is close to zero for a large range of voltage levels but rises sharply once the voltage is past a certain threshold (3.7V for Trio and $2.8 \mathrm{~V}$ for Heliomote). This implies that the useful (most power produced) range of the solar cell in a particular system (indicated by its voltage) is very narrow. Therefore, power tracking circuits or algorithms are only meaningful within this small range.

\subsection{Energy flow and energy efficiency}

As an evaluation metric of a micro-solar power system, we can consider energy efficiency, which is defined as the rate of the amount of solar energy used for useful work (energy stored in the storage or energy consumed by sensor node):

$$
\text { Efficiency }=\left(E_{b a t}+E_{c a p}+E_{c o n s}\right) / E_{\text {sol }}
$$

We set up the experiment as in Figure 18 and measured the following characteristics of Trio and Heliomote: solar cell voltage $V_{\text {sol }}(t)$, solar cell current $I_{\text {sol }}(t)$, and voltage levels of the energy storage elements $\left(V_{c a p}(t)\right.$ and $\left.V_{b a t}(t)\right)$. Using
Table 7: Measurement of solar-cell characteristics for Trio and the Heliomote $(10 / 8 / 2006)$.

\begin{tabular}{|r|r|r|r|r|}
\hline \multicolumn{5}{|c|}{ Trio } \\
\hline Time & $I_{s c}(\mathrm{~mA})$ & $V_{o c}(\mathrm{~V})$ & $P_{\max P}(\mathrm{~mW})$ & $P_{o p}(\mathrm{~mW})$ \\
\hline 8:16 AM & 4.96 & 6.52 & 19.90 & 21.72 \\
9:14 AM & 12.04 & 7.10 & 52.96 & 59.67 \\
10:17 AM & 20.51 & 7.28 & 90.37 & 95.50 \\
11:18 AM & 26.18 & 7.30 & 115.55 & 120.85 \\
12:18 PM & 29.47 & 7.31 & 129.07 & 134.83 \\
1:18 PM & 29.45 & 7.41 & 131.65 & 136.10 \\
2:23 PM & 27.38 & 7.29 & 118.88 & 120.81 \\
3:15 PM & 23.49 & 7.17 & 98.81 & 106.69 \\
4:13 PM & 16.40 & 6.82 & 66.32 & 67.82 \\
5:10 PM & 8.24 & 6.42 & 31.61 & 32.09 \\
5:56 PM & 2.75 & 5.19 & 7.59 & 9.97 \\
\hline \multicolumn{5}{|c|}{ Heliomote } \\
\hline Time & $I_{s c}(\mathrm{~mA})$ & $V_{o c}(\mathrm{~V})$ & $P_{\max P}(\mathrm{~mW})$ & $P_{o p}(\mathrm{~mW})$ \\
\hline 9:27 AM & 17.93 & 4.74 & 34.42 & 26.26 \\
10:30 AM & 26.92 & 5.26 & 62.37 & 52.59 \\
11:32 AM & 32.99 & 5.98 & 89.02 & 73.54 \\
12:33 PM & 35.85 & 6.07 & 100.66 & 84.38 \\
1:35 PM & 35.59 & 6.24 & 107.50 & 81.97 \\
2:39 PM & 32.37 & 6.10 & 91.56 & 67.34 \\
3:29 PM & 27.01 & 5.99 & 70.60 & 49.81 \\
4:27 PM & 18.43 & 5.67 & 41.42 & 27.62 \\
5:23 PM & 8.68 & 3.86 & 10.58 & 9.65 \\
6:10 PM & 1.44 & 0.96 & 0.38 & 0.24 \\
\hline
\end{tabular}
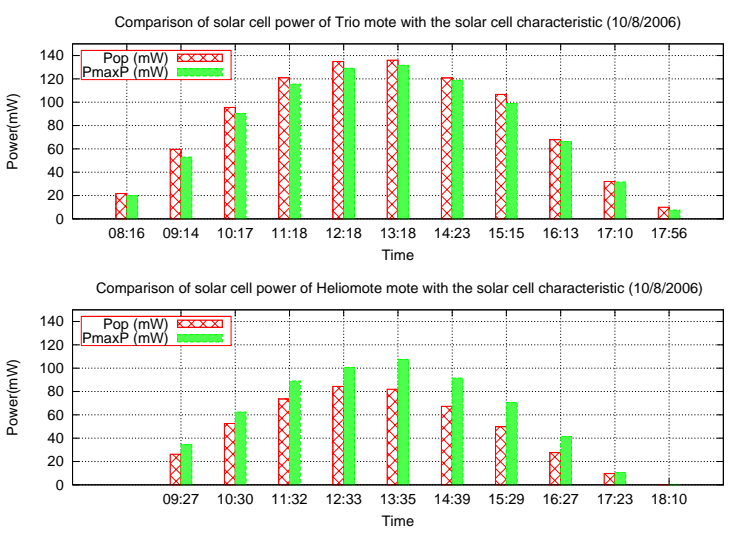

Figure 14: Comparison of $P_{o p}$ and $P_{\max P}$

these measurement data, we can calculate the energy budget and the stored energy for a given period:

- $E_{\text {sol }}(t)=\sum I_{\text {sol }}(t) \cdot V_{\text {sol }}(t) \cdot\left(t_{i}-t_{i-1}\right)$, where $t=t_{k}$

- $E_{c a p}(t)=0.5 \cdot$ Capacitance $\cdot V_{c a p}(t)^{2}$

- $E_{\text {cons }}(t)=V_{\text {mote }} \cdot I_{\text {avg }} \cdot\left(t_{k}-t_{1}\right)$

As for the mote operation, we used the same mote platform Telos rev. B [6] for both Trio and Heliomote. Heliomote was originally reported based on Mica2 mote [7], but it can be configured with a different kind of mote platform and we used the same mote platform as Trio to make a fair comparison. When we set the radio duty-cycle as $1.56 \%$, the average current consumption for one-hour measurement $I_{\text {avg }}$ is $0.5448 \mathrm{~mA}$ (Trio) and $0.4031 \mathrm{~mA}$ (Heliomote). As for the mote voltage $V_{\text {mote }}$, we had Telos mote's nominal voltage of $3.0 \mathrm{~V}$. In order to calculate the energy stored in the battery $E_{b a t}$, we have estimated the voltage-to-energy relation using the manufacturer-provided voltage-to-capacity or voltage-to-discharge time profile (Figure 19). 

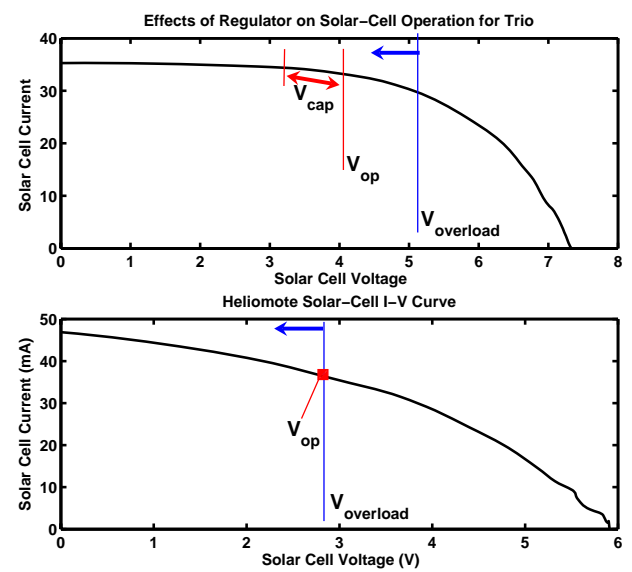

Figure 15: Comparison regulator design

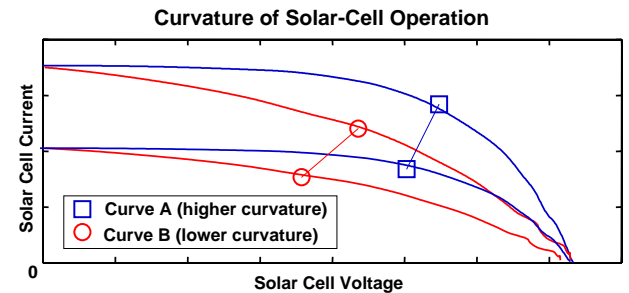

Figure 16: Curvature of solar cell I-V curve and its effect on maximum output power

The energy level trend graphs of Trio and Heliomote (Figure 20 and Figure 21) show that both systems have accumulated the charge in the energy storage while the solar-cell energy levels have increased, and the frequencies of charging are proportional to the solar-cell power. The supercapacitor energy graph shows that the Trio node used the supercapacitor as its power source from 08:15 to 20:15 (Figure 20(b)). During this time, the supercapacitor cycled between charging and discharging, while the energy level of the $\mathrm{Li}^{+}$battery monotonically increased (except the spikes, which are the artifacts of short pulse charging). Whereas, Heliomote handled the charging-discharging cycle directly from the battery, and the battery was discharged for longer hours. This confirms that using two-level energy storage helps reducing the battery discharge frequency, thus saves the effective lifetime of the battery.

Table 8 summarizes the trend of the daily energy level. First, it shows that the battery level gradually has increased with the daily net increase positive, which implies that the Trio node and the Heliomote node have excess energy to store even after the mote consumption and the energy loss. Second, it shows that the supercapacitor of the Trio node keeps about the same about of energy level each day with the net increase close to zero. This implies that the supercapacitor buffers the solar energy transferring the excess energy to the battery. Third, the daily solar energy budget $\Delta E_{\text {sol }}$ varies depending on the solar condition and the battery energy net increase $\Delta E_{b a t}$ shows a positive correlation with the $\Delta E_{\text {sol }}$. Finally, our experiment data shows that about $19.5 \%$ to $33.4 \%$ of solar energy budget was stored in the energy storage or consumed by the Trio node. The Heliomote
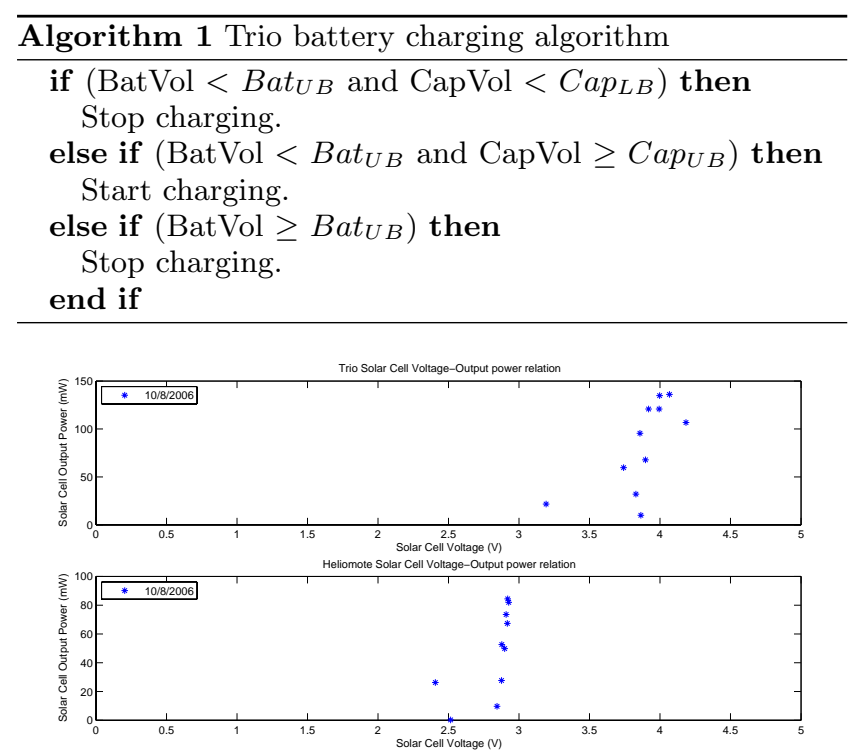

Figure 17: Operating voltage to power relation for Trio and Heliomote.

node has the energy efficiency of $6.9 \%$ to $14.6 \%$.

As for the weather condition for the measurement on each day, we chose the sunny days during in mid-October so that the weather condition is similar to all the measurements. One difference between the measurements of each day is the energy level of the storage elements. This is because we use the same experiment set up over multiple days without depleting the energy storage. This explains the difference in energy level of the storage elements $\left(\Delta E_{b a t}\right)$.

We can see that only a small portion of the solar energy is used for energy storage or mote consumption, and more than $66 \%$ (Trio) or $85 \%$ (Heliomote) of solar energy is wasted. We can list several causes for this energy loss such as DCDC converter, non-ideal round-trip energy efficiency and self discharge of energy storage and over-charge protection regulator. Out of these possible causes of energy loss, we were able to quantify the effect of over-charge protection regulator from our measurement data.

Figure 21(a) shows the trends of solar energy and battery energy of Heliomote. We can see that the battery started being charged from 08:00 where the level of solar energy started to increase. At around 12:00, the battery energy level started to grow very slowly even though solar energy level increased at the same rate. From 13:00, the battery energy level started to drop slowly, which shows that overcharge protection regulator was activated and cut the path from the solar-cell to the battery. While the solar energy was available from 8:00 to 17:00, the Heliomote utilized only during 8:00 to 12:00, which corresponds to around one-third of solar energy income. We can confirm the same effect from Figure 21(b), which shows the trends of solar power and battery energy.

Whereas, the trends of solar energy and battery energy of Trio (Figure 20(a)) show that battery energy level increased at about constant rate as the solar energy increased at about a constant rate from 08:00 to 17:00.

\section{CONCLUSION}



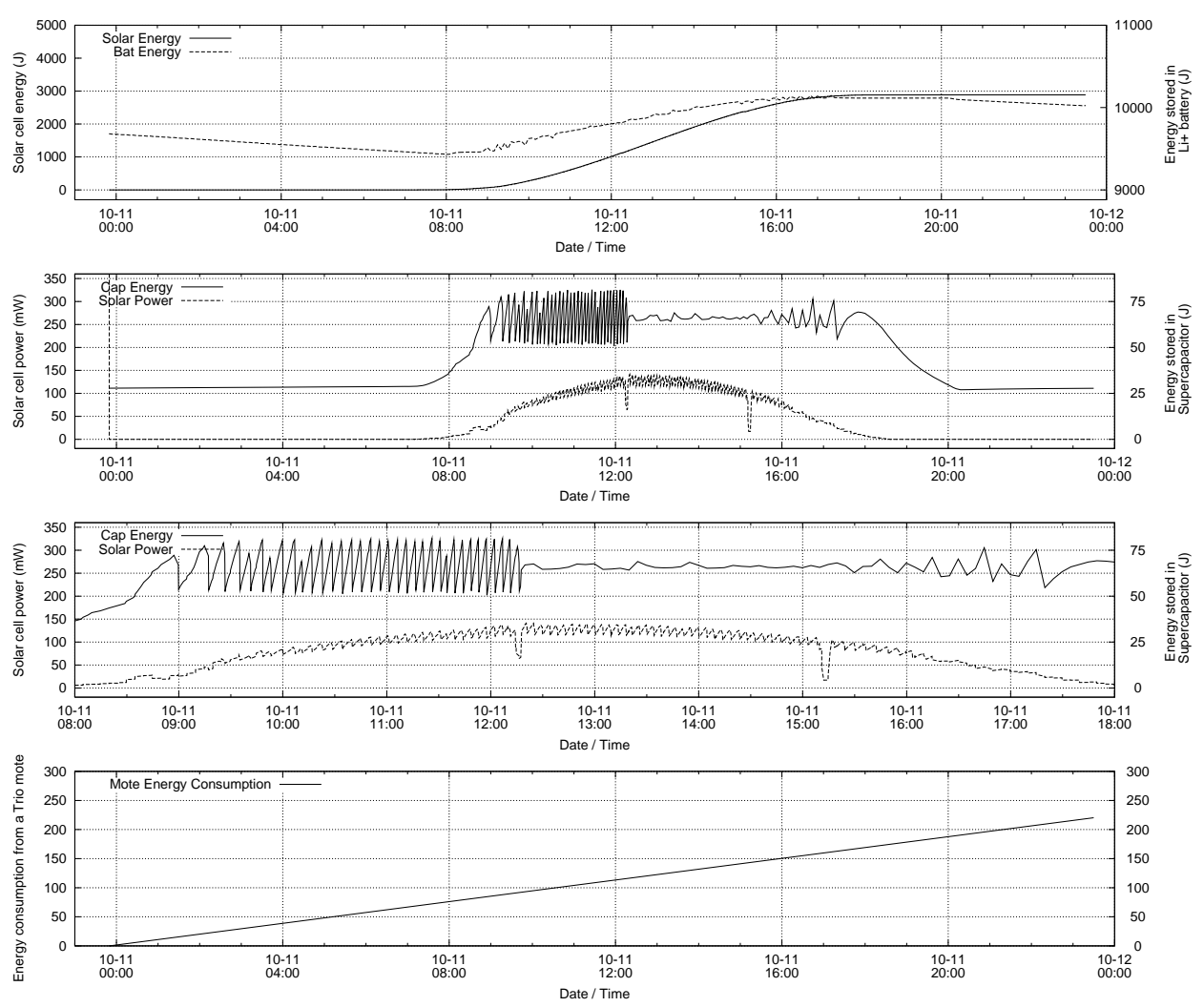

Figure 20: Daily energy trend for the Trio node on 10/11/2006 (sampled every five minutes). (a) Solar-cell energy and battery energy. (b) Solar-cell power and supercapacitor energy. (c) Zoom-in figure for the solarcell power and supercapacitor energy from 8:00 to 18:00 (Since the supercapacitor charged and discharged faster than our sampling frequency of five minutes, the supercapacitor energy graphs show only the average values from 12:15 to 15:30). (d) Estimation of mote energy consumption.
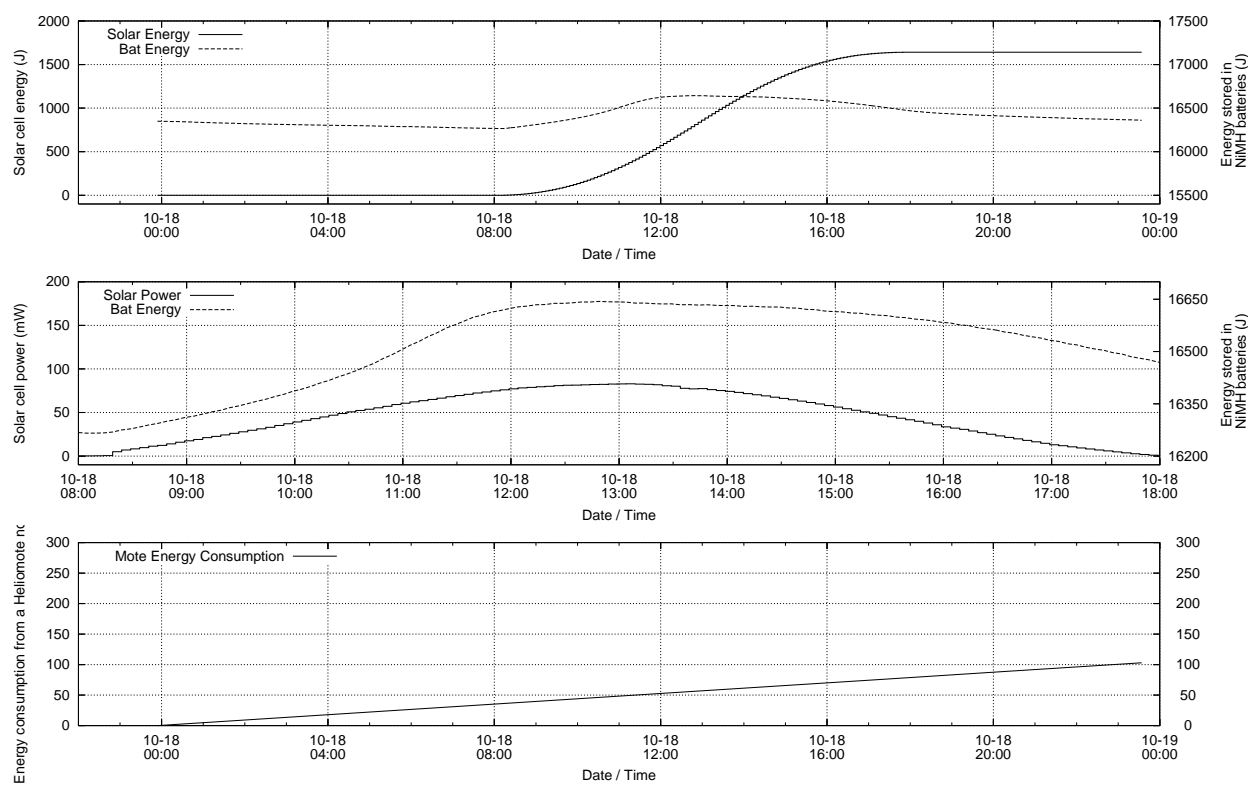

Figure 21: Daily energy trend for the Heliomote node on 10/18/2006 (sampled every five minutes). (a) Solar-cell energy and battery energy. (b) Zoom-in figure for the solar-cell power and battery energy from 08:00 to 18:00. (c) Estimation of mote energy consumption. 

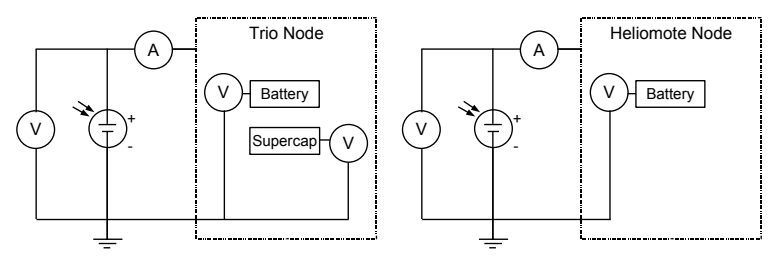

Figure 18: Experiment setup for energy efficiency measurement (a) Trio, (b) Heliomote
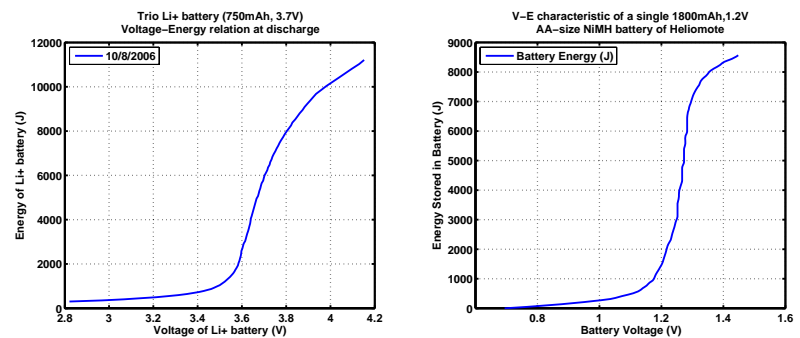

Figure 19: Battery voltage-to-energy relation: (a) Trio, (b) Heliomote

As a way to evaluate various design choices and set guidelines for micro-solar power systems, we presented a system model that consists of four components: environment, sensor node, solar collector and energy storage. As concrete examples of micro-solar power systems, we analyzed two published solar-powered sensor platforms, Trio and Heliomote, which represent two different design points in our model. The analysis of our model and the observation of the two platforms gave us some insight in how to design micro-solar power systems:

- Sensor node: Dynamic duty-cycle adjustment is needed to provide year-round operation where the duty-cycle and sampling rate is higher during summer time. Sensor devices such as photo resistor or Coulomb meter can be used to estimate the varying solar energy.

- Environment: The inclination of the solar cell can be a fixed value to increase the incident solar radiation. Dynamic inclination adjustment, which is employed by some macro-solar systems, involves the mechanical operation and may not be effective to resource constrained micro-solar power systems.

- Solar collector: We have found that the solar-cell operating point that produces usable output power is narrow. By buffering the solar-cell output with supercapacitor and setting the charging and regulator parameters correctly, we can build a solar collector that matches its output power close to the optimum case.

- Energy storage: Long and near-perpetual lifetime is the primary objective of solar-power systems. We have observed that using multi-level energy storage helped improve lifetime by reducing the number of chargedischarge cycles to the storage elements.

\section{REFERENCES}

Table 8: Energy level and efficiency for the Trio node and the Heliomote node

\begin{tabular}{|c|c|c|c|}
\hline \multicolumn{4}{|c|}{ Trio } \\
\hline Date & $10 / 9$ & $10 / 11$ & $10 / 12$ \\
\hline$\Delta E_{\text {sol }}$ & $3031.3 \mathrm{~J}$ & $2885.5 \mathrm{~J}$ & $2870.8 \mathrm{~J}$ \\
\hline$\Delta E_{c a p}$ & $-0.05 \mathrm{~J}$ & $-0.04 \mathrm{~J}$ & $0.16 \mathrm{~J}$ \\
\hline$\Delta E_{b a t}$ & $791.2 \mathrm{~J}$ & $342.1 \mathrm{~J}$ & $348.8 \mathrm{~J}$ \\
\hline$\Delta E_{\text {cons }}$ & $221.0 \mathrm{~J}$ & 220.3J & $221.0 \mathrm{~J}$ \\
\hline$\Delta E_{c a p}+\Delta E_{\text {bat }}+\Delta E_{\text {cons }}$ & $1012.1 \mathrm{~J}$ & $562.4 \mathrm{~J}$ & $569.6 \mathrm{~J}$ \\
\hline$\frac{\Delta E_{c a p}+\Delta E_{b a t}+\Delta E_{c o n s}}{\Delta E_{s o l}}$ & $33.4 \%$ & $19.5 \%$ & $19.8 \%$ \\
\hline \multicolumn{4}{|c|}{ Heliomote } \\
\hline Date & $10 / 14$ & $10 / 16$ & $10 / 18$ \\
\hline$\Delta E_{\text {sol }}$ & 1237.6J & $1449.9 \mathrm{~J}$ & $1641.4 \mathrm{~J}$ \\
\hline$\Delta E_{c a p}$ & - & - & - \\
\hline$\Delta E_{b a t}$ & $27.0 \mathrm{~J}$ & 107.3J & $10.1 \mathrm{~J}$ \\
\hline$\Delta E_{\text {cons }}$ & $103.4 \mathrm{~J}$ & $104.5 \mathrm{~J}$ & $103.0 \mathrm{~J}$ \\
\hline$\Delta E_{c a p}+\Delta E_{b a t}+\Delta E_{c o n s}$ & $130.4 \mathrm{~J}$ & $211.8 \mathrm{~J}$ & $113.1 \mathrm{~J}$ \\
\hline$\frac{\Delta E_{c a p}+\Delta E_{b a t}+\Delta E_{\text {cons }}}{\Delta E_{\text {sol }}}$ & $10.5 \%$ & $14.6 \%$ & $6.9 \%$ \\
\hline
\end{tabular}

[1] Meteonorm. http: //www.meteotest.ch/pdf/am/mn_description.pdf.

[2] P. Dutta, J. Hui, J. Jeong, S. Kim, C. Sharp, J. Taneja, G. Tolle, K. Whitehouse, and D. Culler. Trio: Enabling sustainable and scalable outdoor wireless sensor network deployments. IEEE SPOTS, 2006.

[3] X. Jiang, J. Polastre, and D. Culler. Perpetual environmentally powered sensor networks. IEEE SPOTS, Apr. 2005.

[4] A. Kansal, D. Potter, and M. B. Srivastava. Performance aware tasking for environmentally powered sensor networks. ACM SIGMETRICS, June 2004.

[5] J. Polastre, J. Hill, and D. Culler. Versatile low power media access for wireless sensor networks. $A C M$ Sensys, Nov. 2004.

[6] J. Polastre, R. Szewczyk, and D. Culler. Telos: Enabling ultra-low power wireless research. IEEE SPOTS, Apr. 2005.

[7] V. Raghunathan, A. Kansal, J. Hsu, J. Friedman, and M. Srivastava. Design considerations for solar energy harvesting wireless embedded systems. IEEE SPOTS, 2005.

[8] J. F. Randall. Designing Indoor Solar Products, Photovoltaic Technologies for AES. John Wiley \& Sons, Ltd, 2005.

[9] S. Roundy, B. P. Otis, Y.-H. Chee, J. M. Rabaey, and P. Wright. A 1.9ghz rf transmit beacon using environmentally scavenged energy. IEEE Int. Symposium on Low Power Elec. and Devices, 2003.

[10] P. Sikka, P. Corke, P. Valencia, C. Crossman, D. Swain, and G. Bishop-Hurley. Wireless adhoc sensor and actuator networks on the farm. IEEE SPOTS, 2006.

[11] F. Simjee and P. H. Chou. Everlast: Long-life, supercapacitor-operated wireless sensor node. ISLPED, 2006.

[12] W. Ye, J. Heidemann, and D. Estrin. An energy-efficient mac protocol for wireless sensor networks. IEEE INFOCOM, 2002.

[13] P. Zhang, C. M. Sadler, S. A. Lyon, and M. Martonosi. Hardware design experiences in zebranet. ACM Sensys, 2004. 